Review

\title{
DNT Cell-based Immunotherapy: Progress and Applications
}

\author{
Yingrui $\mathrm{Li}^{1,3}$, Kang Dong${ }^{2}$, Xueke Fan4, Jun $\mathrm{Xie}^{1}$, Miao Wang${ }^{3}$, Songtao Fu${ }^{1 凶}$, Qin $\mathrm{Li}^{3 凶}$ \\ 1. Department of Biochemistry \& Molecular Biology, School of Basic Medical Sciences, Shanxi Medical University, Taiyuan, 030000, China. \\ 2. Shanxi Pharmaceutical Group Gene Biotech co. LTD, Taiyuan, 030000, China. \\ 3. Department of Oncology, Beijing Friendship Hospital, Capital Medical University, Beijing, 100050, China. \\ 4. Department of Gastroenterology, Jincheng People's Hospital, Jincheng, 048000, China.
}

$\square$ Corresponding authors: Dr. Qin Li. Department of Oncology, Beijing Friendship Hospital, Capital Medical University, Beijing, 100050, China. Tel.: +86 10 63139325, Fax: +8610 63139325. E-mail: oncologistinbj@163.com. Or Prof. Songtao Fu. Department of Biochemistry \& Molecular Biology, School of Basic Medical Sciences, Shanxi Medical University, Taiyuan, 030000, China. E-mail: fst7789@sina.com.

(c) The author(s). This is an open access article distributed under the terms of the Creative Commons Attribution License (https://creativecommons.org/licenses/by/4.0/). See http://ivyspring.com/terms for full terms and conditions.

Received: 2019.08.28; Accepted: 2020.02.26; Published: 2020.03.31

\begin{abstract}
Cancer immunotherapy has firmly established a dominant status in recent years. Adoptive cellular immunotherapy $(\mathrm{ACl})$ is the main branch of immunotherapy. Recently, the immune effector cells of $\mathrm{ACl}$, such as T cells, NK cells, and genetically engineered cells, have been used to achieve significant clinical benefits in the treatment of malignant tumors. However, the clinical applications have limitations, including toxicity, unexpectedly low efficiency, high costs and strict technical requirements. More exploration is needed to optimize $\mathrm{ACl}$ for cancer patients. CD3+CD4-CD8- double negative $\mathrm{T}$ cells (DNTs) have emerged as functional antitumor effector cells, according to the definition of adoptive immunotherapy. They constitute a kind of $\mathrm{T}$ cell subset that mediates nontumor antigen-restricted immunity and has important immune regulatory functions. Preclinical experiments showed that DNTs had a dual effect by killing tumor cells and inhibiting graft-versus-host disease. Notably, DNTs can be acquired from healthy donors and expanded in vitro; thus, allogeneic DNTs may be provided as "off-the-shelf" cellular products that can be readily available for direct clinical application. We review the progress and application of DNTs in immunotherapy. DNTs may provide some novel perspectives on cancer immunotherapy.
\end{abstract}

Key words: DNTs, immunotherapy, tumor

\section{Introduction}

Tumor immunity refers to the treatment that activates the human immune system directly or indirectly to kill tumor cells $[1,2]$. In 2018, the Nobel Prize in physiology or medicine was awarded to immunologists for the discovery of treatments that suppress negative immunoregulation, which conferred mainstream status on cancer immunotherapy [3, 4]. Currently, tumor immunotherapies mainly include immune checkpoint inhibitors [5-8], oncolytic viruses [9], antitumor vaccines $[10,11]$ and adoptive cellular immunotherapy (ACI) [12-15]. ACI has been used in the clinic and has achieved great clinical benefits for malignant tumors $[16,17]$.

ACI amplifies and activates autologous and/or allogeneic immune functional cells in vitro, and then, these activated cells are infused into tumor patients to activate the immune response or kill tumor cells directly. ACI has been used in cancer patients, and this treatment includes various immune effector cells such as tumor-infiltrating lymphocytes (TILs) [18-20], natural killer cells (NK) [21], chimeric antigen receptor-modified $\mathrm{T}$ cells (CAR-T) $[15,22]$, and $\mathrm{T}$ cell receptor T-cells [23-25]. ACI has achieved some clinical effects. For example, Zacharakis N [26] screened and expanded TILs from a patient with metastatic breast cancer and transfused these TILs back into the patient. After 42 weeks, the patient's cancer cells could no longer be detected. Maude SL [27] found that 30 children with acute lymphoblastic leukemia had a $90 \%$ remission rate after CAR-T 
therapy. In an ongoing phase II clinical trial (NCT0310 8495), the final effective rate of TILs for advanced cervical cancer was $44 \%$; based on this result, the FDA approved TIL-based therapy LN-145 as a breakthrough treatment for advanced cervical cancer [28].

Although ACI has shown preliminary progress in cancer treatment, many obstacles must be overcome. CAR-T cells can cause severe cytotoxicity, including cytokine release syndrome and neurotoxicity. Highly specific tumor antigens are among the key elements for CAR-T therapy, and the therapeutic effect is reduced in solid tumors because of the loss of specific antigens [29]. Hamieh M and coworkers [30] found that tumor cells could provide specific antigens to CAR-T cells via trogocytosis, which induces antigen loss and CAR-T cell fratricidal killing. In addition, reinfusion of these cells with modified genes increases the cost and potential risk of this treatment [31, 32]. TIL therapies for malignant tumors were performed in early phase clinical trials $[33,34]$, and enrichment of specifically recognized TILs and complicated expansion methods made it difficult to generate therapeutically relevant $\mathrm{T}$ cells. Adotevi and coworkers [35] explored the effect of combining cetuximab and NK cells for patients with hepatic metastases. After reinfusion of these NK cells, the metabolic activity of most intrahepatic metastases was significantly reduced. Four months later, the patients presented with different degrees of progress and developed resistance to NK cell immunotherapy. We need more in-depth exploration to optimize ACI for cancer patients. CD3+CD4-CD8-double negative T cells (DNTs) have emerged as functional immune cells in the field of antitumor therapy because they induce high cytotoxicity in multiple tumor cells in a nonspecific manner without causing graft-versus-host disease (GVHD) [36, 37]. This review covers the sources of DNTs and the research on progress made in relation to cancer immunotherapy, outlines the mechanisms by which DNTs exert immune-response killing effects and explores these outcomes as documented in experimental studies.

\section{The sources of DNTs}

DNTs are regarded as unconventional $\mathrm{T}$ cells that are positive for $\mathrm{T}$ lymphocyte antigen receptors but negative for CD4, CD8 and CD56 surface markers. According to different $\mathrm{T}$ cell receptors (TCRs), DNTs are divided into two groups: $\alpha \beta+D N T s$ and $\gamma \delta+$ DNTs. DNTs comprise $1 \%$ to $5 \%$ of the T cells in the peripheral blood of normal humans [36, 38, 39]. DNTs eliminate malignant tumors in a nontumor antigen-restricted manner, despite expressing TCR and recognizing MHC class molecules. Some studies have shown that DNTs have a strong antitumor effect
[40-42]. Although scientists have recently tried to describe the origin and function of DNTs, the origin and role of DNTs in immune mechanisms have not been fully revealed. DNTs have diverse patterns of expression as cell surface molecules [43] and secrete an extensive array of cytokines, and it has been suggested that they may be derived from different sources or differentiation pathways [37]. The origin of DNTs also may differ among various species [44].

Human T progenitor cells develop in the thymus where they are identified as double-negative thymocytes that do not express the CD4 or CD8 T cell marker [45]. Mature double-negative thymocytes gradually differentiate and pass through an immature CD4 single-positive and CD4 and CD8 double-positive phase, and eventually become a functional mature TCR-expressing CD4 or CD8 single-positive $\mathrm{T}$ cells, after which they leave the thymus [46-49]. Some studies have suggested that DNTs may originate in the thymus to avoid negative selection, and then, DNTs are activated and expanded in the periphery [50-52]. Some studies have shown that DNTs can be transformed from double-positive thymocytes [53]. Crispín and coworkers [54, 55] found that human DNTs can differentiate from activated CD8+ $\mathrm{T}$ cells. In addition, some studies found that CD4+ $\mathrm{T}$ cells can transform into DNTs and that the costimulatory molecules OX40/OX40L enhance this process [56, 57]. Cong $M$ and coworkers [58] also revealed that the transformation of $\mathrm{CD} 4+\mathrm{T}$ cells to DNTs is promoted by IL-2. Grishkan [59] proposed that mouse spleen $\mathrm{CD} 4+\mathrm{T}$ cells stimulated in vitro for longer than 3 weeks can produce DNTs. However, Crispin JC [54] stimulated human CD4+ T cells for 5 days and did not produce DNTs in vitro.

\section{History of DNT-based immunotherapy}

In the past, DNTs were described as regulatory $\mathrm{T}$ cells, and the adoptive transfer of DNTs was found to prevent allograft rejection, GVHD, and autoimmune diabetes [60, 61]. Subsequently, scientists gradually discovered that DNTs had a killing effect on tumor cells. In 2003, Young KJ et al [62] injected lymphoma cells with a single class-I MHC locus mismatched spleen cells into mice and found that more than $75 \%$ of the mice survived indefinitely, and the number of DNTs increased 15-fold in the mice with the lymphoma cells compared to the number in the normal mice. The next experiment proved that DNTs induced cytotoxicity in A20 lymphoma cells in vitro and vivo, indicating that the DNTs had antitumor effects. Voelkl S [63] isolated a group of DNTs from the peripheral blood of melanoma patients that could specifically recognize melanoma-related antigenic peptide gp100, and could induce cytotoxicity in target 
cells expressing gp100 and in HLA-A2+gp100 melanoma cells. Dokouhaki et al [64] found that expanded $\gamma \delta+D N T s$ had a killing effect on lung cancer cells in vitro. Merims $S$ et al [39] found that expanded DNTs from acute myeloid leukemia (AML) patients' peripheral blood could kill both allogeneic and autologous primary leukemic blasts. This study established a method for the expansion of DNTs in vitro that can be used as a new immunotherapy to reduce the risk of AML recurrence in patients. Previous studies were preliminary explorations of the antitumor effects of DNTs. The findings from these studies revealed new possibilities for the use of adoptive T-cell therapy against other human cancers.

\section{Recent progress in DNT-based immunotherapy}

Recently, many studies have explored the killing effect of DNTs on various types of cancers and determined the killing mechanism and clinical application of DNTs in cancer therapy. Xu Hong et al [65] found that DNTs inhibit the growth of pancreatic carcinoma in vivo. Lu Y and other studies [66] demonstrated that DNTs inhibit the growth and infiltration of human pancreatic cancer cells. Interferon-gamma (IFN- $\gamma$ ) factor-associated suicide (Fas)/Fas ligand (FasL) and Nrf-2 may be involved in the killing effect of DNTs. Chen B et al [67] demonstrated the feasibility and benefits of using DNTs after conventional chemotherapy. Yao J et al [68] recently reported that IL-15 enhanced the killing effect of DNTs. Fang et al [69] showed that DNT tumor infiltration increased when combined with anti-PD-1 treatment, which enhanced DNT cell-mediated antitumor effects. Andrea Ponzetta et al [70] studied the role of DNTs in the tumor microenvironment and found that neutrophils can regulate the function of $\alpha \beta+D N T s$ and that $\alpha \beta+D N T s$ may have an essential role in antitumor immunity. In addition, DNT research on other diseases has also shown progress. Tian Dan et al [71] adoptively transferred DNTs into an allergic asthma mouse model and found that DNTs hold potential value for treating allergic asthma. Hsu J et al [72] implemented the adoptive transfer of DNTs into a lung ischemia-reperfusion injury mouse model and demonstrated that DNTs ameliorated the lung injury. These findings provide a further understanding of the immunomodulatory functions of DNTs.

\section{DNT antitumor effects and mechanisms}

\section{Ligand-receptor binding}

DNTs are cytotoxic immune cells that have the inherent ability to eliminate tumor cells in a nontumor antigen-restricted manner. Fas is an important apoptotic signal receptor expressed on lymphoma cells, and it combines with FASL expressed on DNTs to induce apoptosis [17]. Young et al [62] showed that DNTs killed murine A20 lymphoma cells and that the mechanism included, but was not limited to, the Fas/FasL pathway. Chen J et al [73] also showed that DNTs killed pancreatic cancer cells and that the cytotoxic effects depended on Fas/FasL. TNF-related apoptosis-inducing ligand (TRAIL) combines with its associated death receptors, including DR4 and DR5, to initiate the apoptosis pathway [74], and tumor cells exert a greater sensitivity than normal cells to TRAIL [75]. Dokouhaki et al [64] found that NKG2D receptor activation promoted soluble TRAIL production of $\gamma \delta+D N T s$, and soluble TRAIL specifically combined with TRAIL receptors expressed on lung cancer cells to induce apoptosis [76]. Yao J et al [68] showed that DNTs expressed twice as much membrane TRAIL after expanding, and the medium supernatant also detected soluble TRAIL, DNTs induced cytotoxicity in non-small cell lung cancer cells (NSCLCs) depending on the TRAIL pathway. Studies have also shown that the concentration of soluble TRAIL is related to its antitumor activity and clinical response [77]. NK cells, T cells and DNTs express the active receptors NKG2D and DNAM-1. NKG2D mediates cytotoxicity by combining MHC class I polypeptide-related sequence $A$ and B with UL16-binding protein molecules, which are highly expressed on tumor cells [62, 78]. DNAM-1 induces killing by recognizing CD112 and CD155 ligands, which are highly expressed on tumor cells but negligibly expressed on their normal counterparts [68, 79-86]. Lee J et al [36] demonstrated that DNTs recognize and kill acute myeloid cells mainly by activating NKG2D and DNAM-1 receptors. In leukemia cells, DNTs also upregulate antitumor activity by secreting IFN- $\gamma$, which further increases NKG2D and DNAM-1 ligand expression in leukemia cells. $\mathrm{Xu} \mathrm{H}$ [65] verified that DNTs inhibit the growth of pancreatic tumors through the MICA-NKG2D pathway.

\section{Granzyme/perforin-mediated target cell apoptosis}

Perforin, as a kind of cytotoxic molecule, forms a transmembrane tubular structure on the target cell membrane, causing cytotoxic cell death. Granzymes enter the channel formed by perforin to induce target cell apoptosis [87-89]. Merims $S$ et al [39] demonstrated that DNTs expressed higher levels of perforin than CD8+ $\mathrm{T}$ cells in AML patients. When blocking the secretion of perforin from DNTs, the killing effect on tumor cells decreased by $80 \%-97 \%$, which showed that DNTs exerted a killing effect that depended on the perforin/Granzyme B (GZMB) 
pathway. Voelkl S [63] described a kind of human DNT cell clone (T4H2) that targeted melanoma cells in a perforin/GZMB-dependent manner. Lee J et al [36] showed that the inhibitory effects of DNTs on leukemia cell toxicity were largely induced by perforin/GZMB. Yao J et al [68] also showed that perforin/GZMB was involved in the process of killing NSCLCs by allogeneic DNTs.

\section{Cytokines}

Expanded DNTs produce high levels of IFN- $\gamma$ and tumor necrosis factor- $\alpha$ (TNF- $\alpha$ ) in vitro [39, 90-92]. Studies showed that the proliferation and activation of host $\mathrm{T}$ cells was suppressed by IFN- $\gamma$ indirectly, which protected mice against GVHD [62, 93, 94]. Moreover, IFN- $\gamma$ was proven to have a positive therapeutic effect on human malignancies [95-97], and it could promote DNT cell-mediated killing of leukemia cells by facilitating NKG2D and DNAM-1 ligand expression [36]. Furthermore, IFN- $\gamma$ increased Fas and FasL protein expression to inhibit leukemia K562 cell proliferation and promote cell apoptosis [98]. There has been less research on TNF- $\alpha$ mechanisms in relation to DNTs. Meng $\mathrm{H}$ et al [99] reported that TNF- $\alpha$ production were promoted by FasL activation in DNTs, thereby enhancing the proinflammatory effects of DNTs.

\section{Applications of DNTs}

Cytokines activate DNT development, survival and cytotoxicity against tumor cells. DNTs also have a synergistic effect when combined with cytokines, as shown by Zhang ZX and coworkers [100], who proved that DNTs require exogenous IL-2 and IL-4 to expand and survive. In addition, IL-4 also protected DNTs from the apoptosis caused by TCR cross-stimulation [101]. Liu K et al [57] showed that IL-2 stimulated the proliferation of DNTs and DNT secretion of perforin. Our previous results also showed that IL-2 administered in a coculture of DNTs and breast cancer cells enhanced the killing effect. IL-15 has a potent stimulatory effect on cytotoxic immune cells such as IL-2 [102], Yao J et al [68] proposed that allogeneic DNTs effectively kill NSCLCs and inhibit the growth of xenograft tumors. Moreover, IL-15 combined with DNTs induced greater cytotoxicity in NSCLCs by increasing TRAIL production and the expression of effector molecules. Other cytokines that may affect DNTs during the acquisition of cancer immunity need to be studied. Erik Meulmeester et al $[103,104]$ showed that transforming growth factor- $\beta$ (TGF- $\beta$ ) downregulated the expression of NKG2D on the surface of NK cells and inhibited the activation of NK cells by cell contact, which led us to consider whether TGF- $\beta$ might also regulate the activity of DNTs in the same way. In addition, TGF- $\beta$ also inhibited the activity of CD4+ and CD8+ T cells, thereby facilitating the escape of cancer cells from $\mathrm{T}$ cell killing and the generation of a tumor microenvironment that blocks $\mathrm{T}$ cell action. Therefore, DNTs may be considered in combination with TGF- $\beta$ inhibitors; however, whether this combination enhances DNT cytotoxicity remains to be further studied $[105,106]$.

DNTs had a more substantial effect when they were combined with conventional chemotherapy [107]. DNTs prevented resistance to traditional chemotherapy. Chen B [67] et al found that chemotherapy-resistant primary AML samples, after pretreatment with doxorubicin, were more sensitive to the cytotoxic effects of DNTs because of the upregulated expression of NKG2D and DNAM-1 ligands. $\mathrm{Xu} \mathrm{H}$ et al [65] found that DNTs combined with gemcitabine had a better inhibitory effect on transplanted pancreatic tumors in mice. It was also reported that doxorubicin and bortezomib could upregulate the expression of NKG2D and DNAM-1 ligands on melanoma cells [108-111], promoting more effective DNT killing of tumor cells.

DNTs combined with PD-1 inhibitor therapy achieve better efficacy. Fang et al [69] found that allogeneic DNTs from healthy donors killed lung cancer cells, and the combination of a PD-1 inhibitor increased the proportion of DNT infiltration in lung cancer tissues, thus inhibiting the growth of transplanted tumors in mice. These results show that adoptive infusion of DNTs may be a promising option for chemotherapy-resistant cancer, and the combination of DNTs with PD-1 inhibitor therapy may achieve better efficacy than either treatment alone. For all these reasons, we advocate the exploration of combined therapies to unleash the full antitumor potential of DNTs.

\section{Advantages of DNTs}

DNTs can be obtained from healthy volunteers and expanded in vitro. Expanded DNTs cryopreserved under GMP conditions have viability and cytotoxicity that are negligibly affected. The isolation and expansion of DNTs in vitro could prevent the activation of various immunosuppressive mechanisms in the tumor microenvironment. Lee JB and coworkers [86] established a system to expand clinically applicable DNTs derived from healthy volunteers (Figure 1); specifically, they used cytokines to mediate the activation and proliferation of the DNTs in vitro, thereby preventing serious side effects caused by the application of biological agents in vivo. Infusion of allogeneic DNTs does not cause GVHD [112-114], and DNTs can kill cancer cells but are 
harmless to normal cells. Amplified DNTs can kill various tumor cells, such as lymphoma cells, melanoma cells, leukemia cells, pancreatic cancer cells and NSCLCs, via similar mechanisms (Figure 2) [36, $39,68,73,115]$. DNTs showed superior killing against AML cell lines than did activated normal CD8+ T cells or NK cells [36]. DNTs also showed significant cytotoxicity in the tumors of OCI-AML-3 and AML patients that were resistant to NK92-mediated cytotoxicity. DNTs stably present and proliferate after infusion. Young KJ et al [115] injected expanded DNTs with A20 lymphoma cells into immunodeficient mice, and the DNTs in the spleen of the mice were gradually increased and observed in the fifth month of treatment. Amplified DNTs express the effector memory $\mathrm{T}$ cell markers CD45RA, CD44, CD43, and CD49D, and DNTs have a longer duration during the immune response than do central memory T cells [86]. In summary, allogeneic DNTs satisfy the requirements for serving as off-the-shelf $\mathrm{ACIs}$ without genetic modification [86], making them great clinical application prospects. Zhang and coworkers carried out a clinical trial of allogeneic DNT treatment of AML patients (NCT03027102), and the effect of the DNTs on the tumor microenvironment needs confirmation.

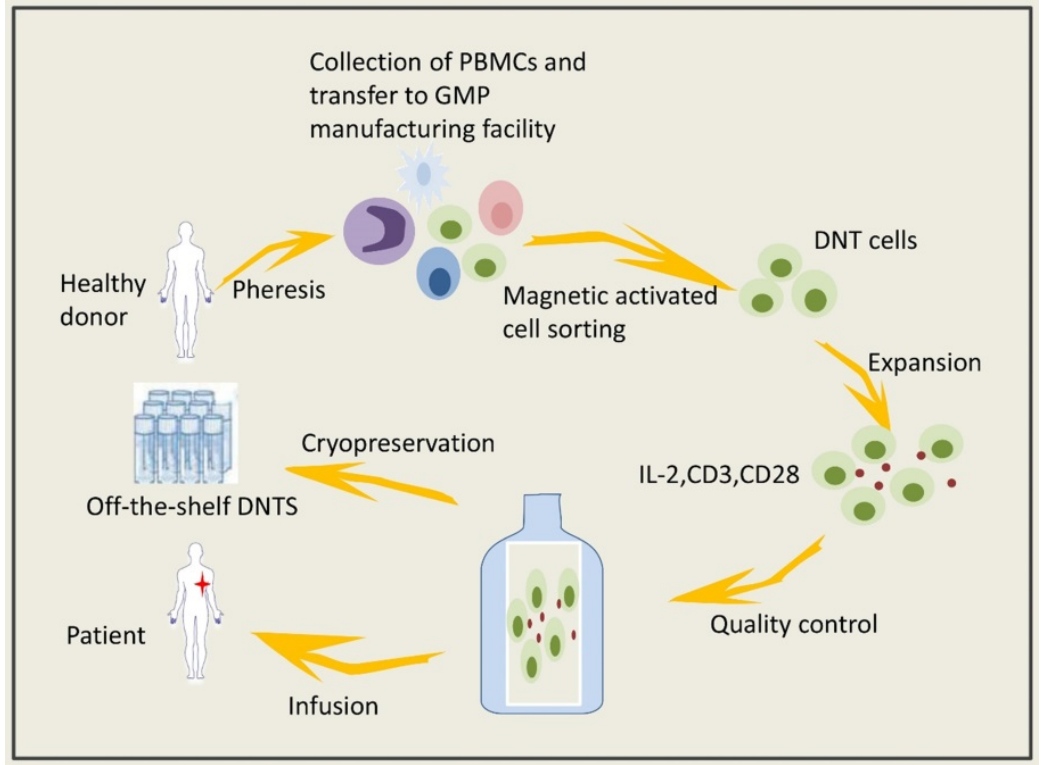

Figure 1. Adoptive DNT-cell based therapy involved steps.

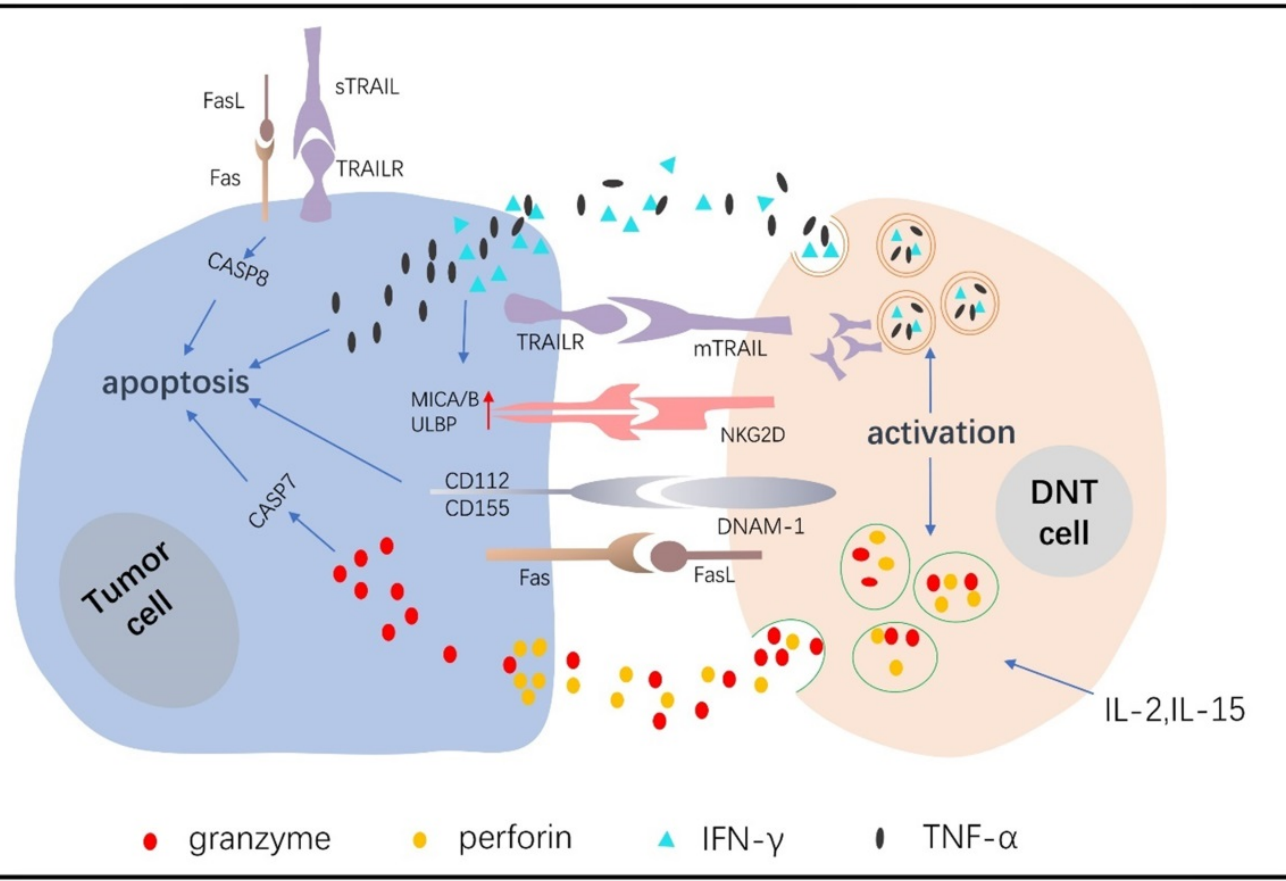

Figure 2. The mechanisms of DNT cells in the control of tumor cells. 


\section{Limitations of DNTs}

DNTs consist of a subpopulation with the CD3+CD56-CD4-CD8- $T$ cell phenotypes and include TCR $\gamma \delta+$ and TCR $\alpha \beta+D N T s$. DNTs in different studies show different antitumor properties due to their heterogeneity. DNTs can survive in the human body for a long time to kill tumor cells. It is beneficial for the sustained killing of tumor cells, but whether long-lived DNTs cause side effects is not completely clear. The safety of long-term application needs further verification. DNTs therapy significantly reduced lung tumor growth in patient-derived xenograft models but could not eradicate the full extent of the tumors; perhaps the lack of memory $\mathrm{T}$ cell formation in the immunodeficient mice was a key factor in this result. In addition, DNTs cannot continually maintain their alertness to tumor cells, and the tumor microenvironment limits the cytotoxicity of DNTs [69].

\section{Conclusions and Prospects}

Allogeneic DNTs derived from healthy humans effectively kill tumor cells in vitro and in vivo. Compared with CAR-T therapy, DNT-based therapy does not depend on genetic modification and does not induce GVHD. DNTs can be acquired from healthy donors and used as an "off-the-shelf" ACI against cancer as promising adaptive immune cells. Summarizing previous studies, we found that most scholars found that DNTs can inhibit the growth of tumor cells. However, most of the studies were limited to cell experiments in vitro or animal studies. These findings cannot directly reveal the role of DNTs in the tumor microenvironment, and the role of DNTs in tumorigenesis and development is not clear. More powerful studies are needed to confirm the hypothesis that DNTs affect tumorigenesis and the microenvironment. This novel family of ACIs may provide new ideas for cancer immunotherapy and improve the long-term prognosis of patients, which is justification for the intense efforts of academic groups in this field.

\section{Abbreviations}

ACI: adoptive cellular immunotherapy; DNTs: double negative $\mathrm{T}$ cells; TIL: tumor-infiltrating lymphocytes; NK: natural killer cells; CAR-T: chimeric antigen receptor - modified T cells; TCR: T cell receptors; GVHD: graft-versus-host disease; AML: acute myeloid leukemia; IFN- $\gamma$ : interferon-gamma; Fas: factor associated suicide; FASL: Fas Ligand; TRAIL: TNF-related apoptosis-inducing ligand; NSCLCs: non-small cell lung cancer cells; GZMB: Granzyme B; TNF-a: tumor necrosis factor- $\alpha$; TGF- $\beta$ : transforming growth factor- $\beta$.

\section{Acknowledgements}

Thank Dan Tian for his advice and guidance.

\section{Funding}

This review is funded by the National Natural Science Foundation of China (Grant NO. 81301912), Beijing Municipal Health System High-level Health Person Foundation Project (Grant NO. 2014-3-005), the Beijing Municipal Science and Technology Commission Foundation (Capital Features, Z161100000516 083, to Qin Li) and Natural Science Foundation of Capital Medical University (to Qin Li).

\section{Competing Interests}

The authors have declared that no competing interest exists.

\section{References}

1. Daniel, Mellman I. Oncology Meets Immunology: The Cancer-Immunity Cycle. Immunity. 2013; 39: 1-10

2. Vanderlugt CL, Miller SD. Epitope spreading in immune-mediated diseases: implications for immunotherapy. Nat Rev Immunol. 2002; 2: 85-95.

3. Ledford $\mathrm{H}$, Else $\mathrm{H}$, Warren $\mathrm{M}$. Cancer immunologists scoop medicine Nobel prize. Nature. 2018; 562: 20-1.

4. Jiang X, Li L, Li Y, Li Q. Molecular Mechanisms and Countermeasures of Immunotherapy Resistance in Malignant Tumor. Journal of Cancer. 2019; 10: 1764-71

5. Blank CU, Rozeman EA, Fanchi LF, Sikorska K, van de Wiel B, Kvistborg P, et al. Neoadjuvant versus adjuvant ipilimumab plus nivolumab in macroscopic stage III melanoma. Nat Med. 2018; 24: 1655-61.

6. Cloughesy TF, Mochizuki AY, Orpilla JR, Hugo W, Lee AH, Davidson TB, et al. Neoadjuvant anti-PD-1 immunotherapy promotes a survival benefit with intratumoral and systemic immune responses in recurrent glioblastoma. Nat Med. 2019; 25: 477-86.

7. Huang AC, Orlowski RJ, Xu X, Mick R, George SM, Yan PK, et al. A single dose of neoadjuvant PD-1 blockade predicts clinical outcomes in resectable melanoma. Nat Med. 2019; 25: 454-61.

8. Kowanetz M, Zou W, Gettinger SN, Koeppen H, Kockx M, Schmid P, et al. Differential regulation of PD-L1 expression by immune and tumor cells in NSCLC and the response to treatment with atezolizumab (anti-PD-L1). Proc Natl Acad Sci U S A. 2018; 115: E10119-e26.

9. Twumasi-Boateng K, Pettigrew JL, Kwok YYE, Bell JC, Nelson BH. Publisher Correction: Oncolytic viruses as engineering platforms for combination immunotherapy. Nature reviews Cancer. 2018; 18: 526.

10. Ott PA, Hu Z, Keskin DB, Shukla SA, Sun J, Bozym DJ, et al. An immunogenic personal neoantigen vaccine for patients with melanoma. Nature. 2017; 547: 217-21.

11. Sahin U, Derhovanessian E, Miller M, Kloke BP, Simon P, Lower M, et al. Personalized RNA mutanome vaccines mobilize poly-specific therapeutic immunity against cancer. Nature. 2017; 547: 222-6.

12. Beatty GL, O'Hara MH, Lacey SF, Torigian DA, Nazimuddin F, Chen F, et al. Activity of Mesothelin-Specific Chimeric Antigen Receptor T Cells Against Pancreatic Carcinoma Metastases in a Phase 1 Trial. Gastroenterology. 2018; 155: 29-32.

13. Ishikawa T, Okayama T, Sakamoto N, Ideno M, Oka K, Enoki T, et al. Phase I clinical trial of adoptive transfer of expanded natural killer cells in combination with IgG1 antibody in patients with gastric or colorectal cancer. Int J Cancer. 2018; 142: 2599-609.

14. Nguyen LT, Saibil SD, Sotov V, Le MX, Khoja L, Ghazarian D, et al. Phase II clinical trial of adoptive cell therapy for patients with metastatic melanoma with autologous tumor-infiltrating lymphocytes and low-dose interleukin-2. Cancer Immunol Immunother. 2019; 68: 773-85.

15. Raje N, Berdeja J, Lin Y, Siegel D, Jagannath S, Madduri D, et al. Anti-BCMA CAR T-Cell Therapy bb2121 in Relapsed or Refractory Multiple Myeloma. N Engl J Med. 2019; 380: 1726-37.

16. Guedan S, Ruella M, June CH. Emerging Cellular Therapies for Cancer. Annu Rev Immunol. 2019; 37: 145-71.

17. Abbasi J. Amid FDA Approval Filings, Another CAR-T Therapy Patient Death. JAMA. 2017;317(22): 2271.

18. Dieci MV, Mathieu MC, Guarneri V, Conte P, Delaloge S, Andre F, et al. Prognostic and predictive value of tumor-infiltrating lymphocytes in two phase III randomized adjuvant breast cancer trials. Annals of oncology : official journal of the European Society for Medical Oncology. 2015; 26: 1698-704. 
19. Ingold Heppner B, Untch M, Denkert C, Pfitzner BM, Lederer B, Schmitt W, et al. Tumor-Infiltrating Lymphocytes: A Predictive and Prognostic Biomarker in Neoadjuvant-Treated HER2-Positive Breast Cancer. Clin Cancer Res. 2016; 22: 5747-54.

20. Luen SJ, Salgado R, Fox S, Savas P, Eng-Wong J, Clark E, et al. Tumour-infiltrating lymphocytes in advanced HER2-positive breast cancer treated with pertuzumab or placebo in addition to trastuzumab and docetaxel: a retrospective analysis of the CLEOPATRA study. The Lancet Oncology. 2017; 18: 52-62.

21. Shah N, Li L, McCarty J, Kaur I, Yvon E, Shaim H, et al. Phase I study of cord blood-derived natural killer cells combined with autologous stem cell transplantation in multiple myeloma. British Journal of Haematology. 2017; 177: 457-66.

22. Zhang C, Wang Z, Yang Z, Wang M, Li S, Li Y, et al. Phase I Escalating-Dose Trial of CAR-T Therapy Targeting CEA(+) Metastatic Colorectal Cancers. Molecular therapy : the journal of the American Society of Gene Therapy. 2017; 25 : 1248-58

23. Ikeda H. T-cell adoptive immunotherapy using tumor-infiltrating $\mathrm{T}$ cells and genetically engineered TCR-T cells. International immunology. 2016; 28: 349-53.

24. Zhu W, Peng Y, Wang L, Hong Y, Jiang X, Li Q, et al. Identification of alpha-fetoprotein-specific $\mathrm{T}$-cell receptors for hepatocellular carcinoma immunotherapy. Hepatology. 2018; 68: 574-89.

25. Tawara I, Kageyama S, Miyahara Y, Fujiwara H, Nishida T, Akatsuka Y, et al. Safety and persistence of WT1-specific T-cell receptor gene-transduced lymphocytes in patients with AML and MDS. Blood. 2017; 130: 1985-94.

26. Zacharakis $\mathrm{N}$, Chinnasamy H, Black M, Xu H, Lu Y-C, Zheng Z, et al. Immune recognition of somatic mutations leading to complete durable regression in metastatic breast cancer. Nature Medicine. 2018; 24: 724-30.

27. Maude SL, Frey N, Shaw PA, Aplenc R, Barrett DM, Bunin NJ, et al. Chimeric antigen receptor T cells for sustained remissions in leukemia. N Engl J Med. 2014; 371: 1507-17.

28. Jazaeri AA, Zsiros E, Amaria RN, Artz AS, Edwards RP, Wenham RM, et al. Safety and efficacy of adoptive cell transfer using autologous tumor infiltrating lymphocytes (LN-145) for treatment of recurrent, metastatic, or persistent cervical carcinoma. 2019; 37: 2538.

29. Bonifant CL, Jackson HJ, Brentjens RJ, Curran KJ. Toxicity and management in CAR T-cell therapy. Molecular Therapy - Oncolytics. 2016; 3: 16011.

30. Hamieh M, Dobrin A, Cabriolu A, Van Der Stegen SJC, Giavridis T, Mansilla-Soto J, et al. CAR T cell trogocytosis and cooperative killing regulate tumour antigen escape. Nature. 2019; 568: 112-6.

31. Ritchie DS, Neeson PJ, Khot A, Peinert S, Tai T, Tainton K, et al. Persistence and efficacy of second generation CAR T cell against the LeY antigen in acute myeloid leukemia. Molecular therapy : the journal of the American Society of Gene Therapy. 2013; 21: 2122-9.

32. Wang QS, Wang Y, Lv HY, Han QW, Fan H, Guo B, et al. Treatment of CD33-directed chimeric antigen receptor-modified $T$ cells in one patient with relapsed and refractory acute myeloid leukemia. Molecular therapy : the journal of the American Society of Gene Therapy. 2015; 23: 184-91.

33. Zacharakis N, Chinnasamy H, Black M, Xu H, Lu YC, Zheng Z, et al. Immune recognition of somatic mutations leading to complete durable regression in metastatic breast cancer. Nat Med. 2018; 24: 724-30.

34. Tran E, Robbins PF, Lu YC, Prickett TD, Gartner JJ, Jia L, et al. T-Cell Transfer Therapy Targeting Mutant KRAS in Cancer. N Engl J Med. 2016; 375: 2255-62.

35. Adotevi $\mathrm{O}$, Godet $\mathrm{Y}$, Galaine J, et al. In situ delivery of allogeneic natural killer cell $(\mathrm{NK})$ combined with Cetuximab in liver metastases of gastrointestinal carcinoma: A phase I clinical trial. Oncoimmunology. 2018;7(5): e1424673.

36. Lee J, Minden MD, Chen WC, Streck E, Chen B, Kang H, et al. Allogeneic Human Double Negative T Cells as a Novel Immunotherapy for Acute Myeloid Leukemia and Its Underlying Mechanisms. Clin Cancer Res. 2018; 24: 370-82.

37. D'Acquisto F, Crompton T. CD3+CD4-CD8- (double negative) T cells: saviours or villains of the immune response? Biochem Pharmacol. 2011; 82: 333-40.

38. Fischer K, Voelkl S, Heymann J, Przybylski GK, Mondal K, Laumer M, et al. Isolation and characterization of human antigen-specific TCR alpha beta+ CD4(-)CD8- double-negative regulatory T cells. Blood. 2005; 105: 2828-35.

39. Merims S, Li X, Joe B, Dokouhaki P, Han M, Childs RW, et al. Anti-leukemia effect of ex vivo expanded DNT cells from AML patients: a potential novel autologous T-cell adoptive immunotherapy. Leukemia. 2011; 25: 1415-22.

40. Alnaggar M, Xu Y, Li J, He J, Chen J, Li M, et al. Allogenic Vgamma9Vdelta2 T cell as new potential immunotherapy drug for solid tumor: a case study for cholangiocarcinoma. J Immunother Cancer. 2019; 7: 36.

41. Chitadze G, Oberg HH, Wesch D, Kabelitz D. The Ambiguous Role of $\gamma \delta \mathrm{T}$ Lymphocytes in Antitumor Immunity. Trends Immunol. 2017; 38(9): 668-678.

42. Kabelitz D, Wesch D, He W. Perspectives of gammadelta T cells in tumor immunology. Cancer Res. 2007; 67: 5-8.

43. Hillhouse EE, Lesage S. A comprehensive review of the phenotype and function of antigen-specific immunoregulatory double negative $\mathrm{T}$ cells. Journal of autoimmunity. 2013; 40: 58-65.

44. Martina MN, Noel S, Saxena A, Rabb H, Hamad AR. Double negative (DN) alphabeta T cells: misperception and overdue recognition. Immunol Cell Biol. 2015; 93: 305-10.

45. Dik WA, Pike-Overzet K, Weerkamp F, De Ridder D, De Haas EFE, Baert MRM, et al. New insights on human T cell development by quantitative T cell receptor gene rearrangement studies and gene expression profiling. 2005; 201: 1715-23

46. Spits H. Development of alphabeta $\mathrm{T}$ cells in the human thymus. Nat Rev Immunol. 2002; 2: 760-72.

47. Petrie HT, Zuniga-Pflucker JC. Zoned out: functional mapping of stromal signaling microenvironments in the thymus. Annu Rev Immunol. 2007; 25: 649-79.

48. Fowlkes BJ, Edison L, Mathieson BJ, Chused TM. Early T lymphocytes. Differentiation in vivo of adult intrathymic precursor cells. 1985. Journal of immunology (Baltimore, Md : 1950). 2009; 183: 5-25.

49. Staal FJ, Weerkamp F, Langerak AW, Hendriks RW, Clevers HC. Transcriptional control of t lymphocyte differentiation. Stem Cells. 2001; 19(3): 165-79.

50. Priatel JJ, Utting $\mathrm{O}$, Teh HS. TCR/Self-Antigen Interactions Drive Double-Negative $\mathrm{T}$ Cell Peripheral Expansion and Differentiation into Suppressor Cells. 2001; 167: 6188-94.

51. Pobezinsky LA, Angelov GS, Tai X, Jeurling S, Van Laethem F, Feigenbaum L, et al. Clonal deletion and the fate of autoreactive thymocytes that survive negative selection. Nature Immunology. 2012; 13: 569-78.

52. Mixter PF, Russell JQ, Morrissette GJ, Charland C, Aleman-Hoey D, Budd RC. A model for the origin of TCR-alphabeta+ CD4-CD8- B220+ cells based on high affinity TCR signals. J Immunol. 1999; 162(10): 5747-56

53. Wang R, Wang-Zhu Y, Grey $H$. Interactions between double positive thymocytes and high affinity ligands presented by cortical epithelial cells generate double negative thymocytes with $\mathrm{T}$ cell regulatory activity. 2002; 99: 2181-6.

54. Crispin JC, Tsokos GC. Human TCR- + CD4- CD8- T Cells Can Derive from CD8+ T Cells and Display an Inflammatory Effector Phenotype. 2009; 183: $4675-81$

55. Ford MS, Zhang ZX, Chen W, Zhang L. Double-Negative T Regulatory Cells Can Develop Outside the Thymus and Do Not Mature from CD8+ T Cell Precursors. 2006; 177: 2803-9.

56. Zhang D, Yang W, Degauque N, Tian Y, Mikita A, Zheng XX. New differentiation pathway for double-negative regulatory $\mathrm{T}$ cells that regulates the magnitude of immune responses. Blood. 2007; 109: 4071-9.

57. Liu K, Ye H, Zhou J, Tian Y, Xu H, Sun X, et al. Ox40 regulates the conversion and suppressive function of double-negative regulatory $\mathrm{T}$ cells. Int Immunopharmacol. 2018; 65: 16-22.

58. Cong M, Liu TH, Tian D, Guo HB, Wang P, Liu K, et al. Interleukin-2 Enhances the Regulatory Functions of CD4(+) T Cell-Derived CD4(-)CD8(-) Double Negative T Cells. Journal of Interferon and Cytokine Research. 2016; 36: 499-505.

59. Grishkan IV, Ntranos A, Calabresi PA, Gocke AR. Helper T cells down-regulate CD4 expression upon chronic stimulation giving rise to double-negative T cells. Cellular immunology. 2013; 284: 68-74.

60. Juvet SC, Zhang L. Double negative regulatory T cells in transplantation and autoimmunity: recent progress and future directions. Journal of molecular cell biology. 2012; 4: 48-58.

61. Liu T, Cong M, Sun G, Wang P, Tian Y, Shi W, et al. Combination of double negative $T$ cells and anti-thymocyte serum reverses type 1 diabetes in NOD mice. J Transl Med. 2016; 14: 57.

62. Kevin J. Young LSK, M. James Phillips and Li Zhang. Antitumor activity mediated by double-negative T cells. Cancer Res. 2003; 63(22): 8014-21.

63. Voelkl S, Moore TV, Rehli M, Nishimura MI, Mackensen A, Fischer K. Characterization of MHC class-I restricted TCRalphabeta+ CD4- CD8- double negative $\mathrm{T}$ cells recognizing the gp100 antigen from a melanoma patient after gp100 vaccination. Cancer Immunol Immunother. 2009; 58(5): 709-18.

64. Dokouhaki P, Schuh NW, Joe B, et al. NKG2D regulates production of soluble TRAIL by ex vivo expanded human $\gamma \delta$ T cells. Eur J Immunol. 2013; 43(12): 3175-82

65. Xu H, Zhu XX, Chen J. DNT cell inhibits the growth of pancreatic carcinoma via abnormal expressions of NKG2D and MICA in vivo. Biochem Biophys Res Commun. 2016; 469: 145-50.

66. Lu Y, Hu P, Zhou H, Yang Z, Sun YU, Hoffman RM, et al. Double-negative T Cells Inhibit Proliferation and Invasion of Human Pancreatic Cancer Cells in Co-culture. Anticancer Res. 2019; 39: 5911-8.

67. Chen B, Lee JB, Kang H, Minden MD, Zhang L. Targeting chemotherapy-resistant leukemia by combining DNT cellular therapy with conventional chemotherapy. J Exp Clin Cancer Res. 2018; 37: 88.

68. Yao J, Ly D, Dervovic D, Fang L, Lee JB, Kang H, et al. Human double negative $\mathrm{T}$ cells target lung cancer via ligand-dependent mechanisms that can be enhanced by IL-15. J Immunother Cancer. 2019; 7: 17.

69. Fang L, Ly D, Wang SS, Lee JB, Kang H, Xu H, et al. Targeting late-stage non-small cell lung cancer with a combination of DNT cellular therapy and PD-1 checkpoint blockade. J Exp Clin Cancer Res. 2019; 38: 123.

70. Ponzetta A, Carriero R, Carnevale S, Barbagallo M, Molgora M, Perucchini C, et al. Neutrophils Driving Unconventional T Cells Mediate Resistance against Murine Sarcomas and Selected Human Tumors. Cell. 2019; 178(2): 346-360.e24.

71. Tian D, Yang L, Wang S, Zhu Y, Shi W, Zhang C, et al. Double negative T cells mediate Lag3-dependent antigen-specific protection in allergic asthma. Nature communications. 2019; 10: 4246.

72. Hsu J, Krishnan A, Lee SA, Dodd OJ, Kim BS, Illei P, et al. CD3(+)CD4(-)CD8(-) Double-negative alphabeta $\mathrm{T}$ cells attenuate lung ischemia-reperfusion injury. J Thorac Cardiovasc Surg. 2009; [Epub ahead of print]. 
73. Chen J, Hu P, Wu G, Zhou H. Antipancreatic cancer effect of DNT cells and the underlying mechanism. Pancreatology. 2019; 19(1): 105-113.

74. Yuan X, Gajan A, Chu Q, Xiong H, Wu K, Wu GS. Developing TRAIL/TRAIL death receptor-based cancer therapies. Cancer metastasis reviews. 2018; 37: 733-48.

75. Walczak H, Miller RE, Ariail K, Gliniak B, Griffith TS, Kubin M, et al. Tumoricidal activity of tumor necrosis factor-related apoptosis-inducing ligand in vivo. Nat Med. 1999; 5: 157-63.

76. Koç Erbaşoğlu Ö, Horozoğlu C, Ercan Ş, Kara HV, Turna A, Farooqi AA, et al. Effect of trail C1595T variant and gene expression on the pathogenesis of non-small cell lung cancer. Libyan Journal of Medicine. 2019; 14: 1535746.

77. Dieli F, Vermijlen D, Fulfaro F, et al. Targeting human \{gamma\}delta\} T cells with zoledronate and interleukin-2 for immunotherapy of hormone-refractory prostate cancer. Cancer Res. 2007; 67(15): 7450-7.

78. Bilotta MT, Abruzzese MP, Molfetta R, et al. Activation of liver X receptor up-regulates the expression of the NKG2D ligands MICA and MICB in multiple myeloma through different molecular mechanisms. FASEB J. 2019; 33(8): 9489-9504.

79. El-Sherbiny YM, Meade JL, Holmes TD, et al. The requirement for DNAM-1, NKG2D, and NKp46 in the natural killer cell-mediated killing of myeloma cells. Cancer Res. 2007; 67(18): 8444-9.

80. Chen B, Lee JB, Kang H, Minden MD, Zhang L. Targeting chemotherapy-resistant leukemia by combining DNT cellular therapy with conventional chemotherapy. J Exp Clin Cancer Res. 2018; 37(1): 88.

81. Gertner-Dardenne J, Castellano R, Mamessier E, et al. Human V $\gamma 9 \mathrm{~V} \delta 2 \mathrm{~T}$ cells specifically recognize and kill acute myeloid leukemic blasts. J Immunol. 2012; 188(9): 4701-8.

82. Chan CJ, Andrews DM, McLaughlin NM, et al. DNAM-1/CD155 interactions promote cytokine and NK cell-mediated suppression of poorly immunogenic melanoma metastases. J Immunol. 2010; 184(2): 902-11.

83. Brooks I, Fleischmann-Mundt B, Woller $\mathrm{N}$, et al. Perioperative, Spatiotemporally Coordinated Activation of $\mathrm{T}$ and NK Cells Prevents Recurrence of Pancreatic Cancer. Cancer Res. 2018; 78(2): 475-488.

84. Champsaur M, Lanier LL. Effect of NKG2D ligand expression on host immune responses. Immunol Rev. 2010; 235(1): 267-85.

85. Ding H, Yang X, Wei Y. Fusion Proteins of NKG2D/NKG2DL in Cancer Immunotherapy. Int J Mol Sci. 2018; 19(1): 177.

86. Lee JB, Kang H, Fang L, D'Souza C, Adeyi O, Zhang L. Developing Allogeneic Double-Negative T Cells as a Novel Off-the-Shelf Adoptive Cellular Therapy for Cancer. Clin Cancer Res. 2019; 25(7): 2241-2253.

87. Bae S, Oh K, Kim H, et al. The effect of alloferon on the enhancement of NK cell cytotoxicity against cancer via the up-regulation of perforin/granzyme B secretion. Immunobiology. 2013; 218(8): 1026-33.

88. Hodge G, Barnawi J, Jurisevic C, Moffat D, Holmes M, Reynolds PN, et al. Lung cancer is associated with decreased expression of perforin, granzyme B and interferon (IFN)-gamma by infiltrating lung tissue T cells, natural killer (NK) T-like and NK cells. Clin Exp Immunol. 2014; 178: 79-85.

89. Vermijlen D, Froelich CI, Luo D, Suarez-Huerta N, Robaye B, Wisse E. Perforin and granzyme B induce apoptosis in FasL-resistant colon carcinoma cells. Cancer Immunol Immunother. 2001; 50: 212-7.

90. Mou Z, Liu D, Okwor I, Jia P, Orihara K, Uzonna JE. MHC class II restricted innate-like double negative $\mathrm{T}$ cells contribute to optimal primary and secondary immunity to Leishmania major. PLoS pathogens. 2014; 10: e1004396.

91. Antonelli LR, Dutra WO, Oliveira RR, Torres KC, Guimaraes LH, Bacellar O, et al. Disparate immunoregulatory potentials for double-negative (CD4- CD8-) alpha beta and gamma delta $\mathrm{T}$ cells from human patients with cutaneous leishmaniasis. Infection and immunity. 2006; 74: 6317-23.

92. Gollob KJ, Antonelli LR, Faria DR, Keesen TS, Dutra WO. Immunoregulatory mechanisms and CD4-CD8- (double negative) T cell subpopulations in human cutaneous leishmaniasis: a balancing act between protection and pathology. Int Immunopharmacol. 2008; 8: 1338-43.

93. Baker J, Verneris MR, Ito M, Shizuru JA, Negrin RS. Expansion of cytolytic CD8(+) natural killer T cells with limited capacity for graft-versus-host disease induction due to interferon gamma production. Blood. 2001; 97: 2923-31.

94. Sang W, Zhang C, Zhang D, Wang Y, Sun C, Niu M, et al. MicroRNA-181a, a potential diagnosis marker, alleviates acute graft versus host disease by regulating IFN-gamma production. Am J Hematol. 2015; 90(11): 998-1007.

95. Garris CS, Arlauckas SP, Kohler RH, Trefny MP, Garren S, Piot C, et al. Successful Anti-PD-1 Cancer Immunotherapy Requires T Cell-Dendritic Cell Crosstalk Involving the Cytokines IFN-gamma and IL-12. Immunity. 2018; 49: 1148-61.e7.

96. Li J, Zhang Y, Chen L, et al. Cervical Cancer HeLa Cell Autocrine Apoptosis Induced by Coimmobilized IFN- $\gamma$ plus TNF-a Biomaterials. ACS Appl Mater Interfaces. 2018; 10(10): 8451-8464.

97. Takeda $\mathrm{K}$, Nakayama $\mathrm{M}$, Hayakawa $\mathrm{Y}$, et al. IFN- $\gamma$ is required for cytotoxic $\mathrm{T}$ cell-dependent cancer genome immunoediting. Nat Commun. 2017; 8: 14607.

98. Xia HL, Li CJ, Hou XF, Zhang H, Wu ZH, Wang J. Interferon- $\gamma$ affects leukemia cell apoptosis through regulating Fas/FasL signaling pathway. Eur Rev Med Pharmacol Sci. 2017; 21(9): 2244-2248

99. Meng $\mathrm{H}$, Zhao $\mathrm{H}, \mathrm{Cao} \mathrm{X}$, et al. Double-negative $\mathrm{T}$ cells remarkably promote neuroinflammation after ischemic stroke. Proc Natl Acad Sci U S A. 2019; 116(12): 5558-5563.
100. Zhang ZX, Yang L, Young KJ, DuTemple B, Zhang L. Identification of a previously unknown antigen-specific regulatory $\mathrm{T}$ cell and its mechanism of suppression. Nat Med. 2000; 6: 782-9.

101. Zhang ZX, Young K, Zhang L. CD3+CD4-CD8- alphabeta-TCR+ $\mathrm{T}$ cell as immune regulatory cell. J Mol Med (Berl). 2001; 79(8): 419-27.

102. Waldmann TA, Lugli E, Roederer M, et al. Safety (toxicity), pharmacokinetics, immunogenicity, and impact on elements of the normal immune system of recombinant human IL-15 in rhesus macaques. Blood. 2011; 117(18): 4787-95.

103. Meulmeester E, Ten Dijke P. The dynamic roles of TGF- $\beta$ in cancer. J Pathol. 2011; 223(2): 205-18.

104. Mariathasan S, Turley SJ, Nickles D, Castiglioni A, Yuen K, Wang Y, et al. TGF $\beta$ attenuates tumour response to PD-L1 blockade by contributing to exclusion of T cells. Nature. 2018; 554: 544-8.

105. Principe DR, Park A, Dorman MJ, et al. TGF $\beta$ Blockade Augments PD-1 Inhibition to Promote T-Cell-Mediated Regression of Pancreatic Cancer. Mol Cancer Ther. 2019; 18(3): 613-620.

106. Saito A, Horie M, Micke P, Nagase T. The Role of TGF- $\beta$ Signaling in Lung Cancer Associated with Idiopathic Pulmonary Fibrosis. Int J Mol Sci. 2018; 19(11): 3611

107. Wei Y, Du Q, Jiang X, Li L, Li T, Li M, et al. Efficacy and safety of combination immunotherapy for malignant solid tumors: A systematic review and meta-analysis. Crit Rev Oncol Hematol. 2019; 138: 178-89.

108. Fine JH, Chen P, Mesci A, Allan DS, Gasser S, Raulet DH, et al. Chemotherapy-induced genotoxic stress promotes sensitivity to natural killer cell cytotoxicity by enabling missing-self recognition. Cancer Res. 2010; 70: 7102-13.

109. Soriani A, Zingoni A, Cerboni C, et al. ATM-ATR-dependent up-regulation of DNAM-1 and NKG2D ligands on multiple myeloma cells by therapeutic agents results in enhanced NK-cell susceptibility and is associated with a senescent phenotype. Blood. 2009; 113(15): 3503-11.

110. Soriani A, Fionda C, Ricci B, Iannitto ML, Cippitelli M, Santoni A Chemotherapy-elicited upregulation of NKG2D and DNAM-1 ligands as a therapeutic target in multiple myeloma. Oncoimmunology. 2013; 2: e26663.

111. Cany J, Roeven MWH, Hoogstad-van Evert JS, et al. Decitabine enhances targeting of AML cells by CD34(+) progenitor-derived NK cells in NOD/SCID/IL2Rg(null) mice. Blood. 2018; 131: 202-14.

112. Achita P, Dervovic D, Ly D, Lee JB, Haug T, Joe B, et al. Infusion of ex-vivo expanded human TCR-alphabeta(+) double-negative regulatory $\mathrm{T}$ cells delays onset of xenogeneic graft-versus-host disease. Clin Exp Immunol. 2018; 193: 386-99.

113. Duncan B, Nazarov-Stoica C, Surls J, et al. Double negative (CD3+ 4- 8-) TCR alphabeta splenic cells from young NOD mice provide long-lasting protection against type 1 diabetes. PLoS One. 2010; 5(7): e11427.

114. Su Y, Huang X, Wang S, et al. Double negative Treg cells promote nonmyeloablative bone marrow chimerism by inducing T-cell clonal deletion and suppressing NK cell function. Eur J Immunol. 2012; 42(5): 1216-25.

115. Young KJ, DuTemple B, Zhang Z, Levy G, Zhang L. CD4(-)CD8(-) regulatory T cells implicated in preventing graft-versus-host and promoting graft-versus-leukemia responses. Transplant Proc. 2001; 33(1-2): 1762-3. 